\title{
Treatment processes for contaminated aqueous media
}

\author{
Humphrey Zebulun
}

Published online: 12 March 2011

(C) Springer Science+Business Media, LLC 2011

Following the 2005 INCEED Conference held in Charlotte, North Carolina, USA, a number of candidate papers were submitted by authors for review and consideration for publication in this important Special Edition. Papers in both the technical note (short but important contributions) and full paper formats were considered. This special edition of The Environmentalist Journal focuses on the Treatment Processes for Contaminated Media as it relates to industrial and environmental applications. The contamination of aquifer has been a subject of great importance due to increased mining activities, improper discharge of spent fossil fuels, and the use of chemical fertilizers and pesticides in various agricultural activities. The different articles published in this special edition reflect the advancements that have been made to curb the deleterious effects of these aquatic contaminants.

The proposed method of removing $\mathrm{NO}_{\mathrm{x}}$ through catalytic reduction plays a significant role in reducing acid rain. In agricultural practices, acid rain is a serious problem encountered in developing countries with no catalytic converters installed in exhausts of automobiles. The persistence of $\mathrm{NO}_{\mathrm{x}}$ in the atmosphere also impacts the air quality, which is important especially for people with respiratory problems. The mechanisms proposed in this study for $\mathrm{NO}_{\mathrm{x}}$ oxidation are vital in addressing these problems. The investigation involving the effect of white rot fungi on the remediation of anthracene-contaminated soil promises to prevent the eventual contamination of groundwater by this contaminant. The carcinogenic and teratogenic effects of anthracene have been well documented. It is found from this study that the fluctuating concentrations of anthracene in soil continues to decrease with the time and can be correlated with the secretion of ligninolytic enzymes by white rot fungi. Another investigation covered in this edition includes the application of membrane technology in groundwater purification. As shown in this study, the removal of excess fluoride from underground water can be successfully completed at a low cost. The proposed method of membrane technology can be applied to address the global problem of limited fresh water resources and the demand of improved water quality. In an associated study, the de-fluoridation of groundwater using magnesium oxide was investigated and indicated that this process can be applied in the removal of various contaminants from groundwater through combined precipitation. In the experimental investigation of electrokinetic extraction of lead from kaolinites, the results from the proposed models indicate that electrokinetic extraction can be applied in removing organic and inorganic contaminants from sediments and can be applied to real-time studies as well.

In conclusion, I would like to thank the many reviewers that took out their time to help us with careful and detailed critical reviews of the papers submitted in this edition. I thank them also for all their comments and recommendations, which helped to improve the quality of the articles in this edition.
H. Zebulun ( $₫)$

Engineering Department, ABNA Engineering, Inc,

St. Louis, MO, USA

e-mail: humphzebs@gmail.com 